\title{
Análisis de la dependencia de insumos importados en la industria brasileña entre 2000 y 2014
}

\section{Valéria Silva Mortari y Maria Aparecida Silva Oliveira}

\section{Resumen}

El objetivo del presente trabajo es analizar la dependencia sectorial de insumos importados de la industria brasileña entre 2000 y 2014. Para ello se utilizó el análisis de insumo-producto, se calculó la demanda directa e indirecta de insumos importados de los sectores y se los clasificó de acuerdo con esta. Se constató que los sectores que presentan una baja demanda de insumos importados son aquellos ligados a las industrias de alimentos, madera, productos de madera y corcho y reparación e instalación de máquinas y equipos. Los demás sectores industriales resultaron dependientes de la importación de insumos para realizar sus actividades productivas. La creciente incorporación de insumos importados en el proceso productivo brasileño dio lugar a la apropiación de una parte del dinamismo del sector por el sector externo.

\section{Palabras clave}

Industria, importaciones, análisis de insumo-producto, producción industrial, estadísticas industriales, Brasil

\section{Clasificación JEL}

L60, L160, 014

\section{Autoras}

Valéria Silva Mortari es estudiante de Maestría en el Instituto de Economía y Relaciones Internacionales de la Universidad Federal de Uberlândia (UFU), Brasil. Correo electrónico: valeriasmortari@gmail.com

Maria Aparecida Silva Oliveira es profesora en el Departamento de Economía de la Universidad Federal de São Carlos (UFSCar). Correo electrónico: aparecidaoliveira@ ufscar.br 


\section{Introducción}

La industria constituye un sector de primordial importancia para el desempeño económico de un país, dada su capacidad de producir efectos indirectos intersectoriales en materia de empleo, ingresos y tecnología mediante el establecimiento de cadenas productivas integradas a nivel nacional. De ese modo, el estímulo a la producción de un sector industrial no se limita a este, sino que se extiende a las demás actividades económicas ligadas directa o indirectamente a dicho sector (Hirschman, 1961; Kaldor, 1957). La estructura productiva industrial de un país es de primordial importancia para generar dinamismo, crecimiento y desarrollo económico a corto y largo plazo (Prebisch, 1949; Furtado, 1964)1.

La economía brasileña experimentó profundos cambios estructurales en la década de 1990, no solo en virtud de las medidas de política económica que se adoptaron con el objetivo de estabilizar los precios, sino también de la forma en que se implementaron esas políticas, lo que repercutió negativamente en el sector industrial brasileño. Esto, a su vez, se relaciona con el hecho de que el brusco proceso de apertura económica consistió, entre las principales medidas, en la liberalización de las importaciones, sin la concomitante puesta en práctica de una política industrial que abarcara los diversos sectores de la industria (Kon y Coan, 2009, pág. 13), a fin de protegerlos de la creciente competencia externa. Este proceso de apertura se caracterizó por sucesivas reducciones en las cuotas de importación, seguidas por la apreciación del real, y marcó la transición de la industria brasileña hacia un nuevo régimen de comercio, dejando atrás por lo menos cuatro décadas de fuerte protección contra las importaciones (Moreira, 1999, pág. 295)².

Estas medidas se reflejaron en el aumento continuo y generalizado de las importaciones en el Brasil. Los datos revelan una aceleración del ritmo de importación en el país, principalmente en lo que se refiere a los bienes intermedios, que tienen un peso cada vez mayor en la estructura de las importaciones brasileñas y muestran una tendencia creciente para los próximos años, como se puede apreciar en el gráfico 1. Se observa que el valor de las importaciones aumenta de modo significativo en relación con el producto interno bruto (PIB) al final de la década de 1990 y se mantiene en un nivel elevado durante la década de 2000.

Teniendo en cuenta el largo proceso de apertura comercial concomitante a la apreciación cambiaria, la dependencia del sector externo de la actividad industrial brasileña ha aumentado gradualmente, pues cada vez se incorporan más componentes y productos importados en la producción industrial ${ }^{3}$.

Según Morceiro, Gomes y Magacho (2014), entre 2003 y 2008 se registró un aumento generalizado de los insumos importados, que llegaron a aproximadamente el 60\% (o más) de los insumos comercializables utilizados en la producción. De esta manera, la industria ha venido perdiendo peso en la contribución al crecimiento del PIB y la generación de empleo. Otra consecuencia sería el debilitamiento de los eslabones productivos (Marconi y Barbi, 2010; Fonseca, 2010: Morceiro, 2012; Magacho, 2010 y 2013; Morceiro, Gomes y Magacho, 2014), o sea, una menor interdependencia sectorial en la economía. Los autores demuestran además que la mayor proporción de insumos importados se destina a la producción de bienes de alta tecnología, de manera que el valor agregado generado por esas industrias pasa al sector externo.

\footnotetext{
1 Véase también Nakabashi, Scatolin y da Cruz (2010).

2 Según Cardoso (2001), el Plan Real - cuyo objetivo era combatir la inflación crónica- pasó por tres etapas: búsqueda del equilibrio en las cuentas gubernamentales, instauración de una reforma monetaria y uso del tipo de cambio como ancla nominal. La combinación de estas políticas económicas llevó a un incremento considerable de la tasa real de interés, que promovió una entrada significativa de capitales en el país y se tradujo en la apreciación del tipo de cambio. Esta, combinada con las políticas de liberalización comercial, perjudicó al sector industrial y provocó un aumento del desempleo (Cardoso, 2001, pág. 12).

3 Véanse Fonseca, Carvalho y Pourchet (1998); Levy y Serra (2002); Feijó, Carvalho y Almeida (2005); y Fonseca (2010).
} 


\section{Gráfico 1}

Brasil: importaciones en valores corrientes y en relación con el producto interno bruto (PIB), 1996-2013

(En miles de reales y porcentajes)

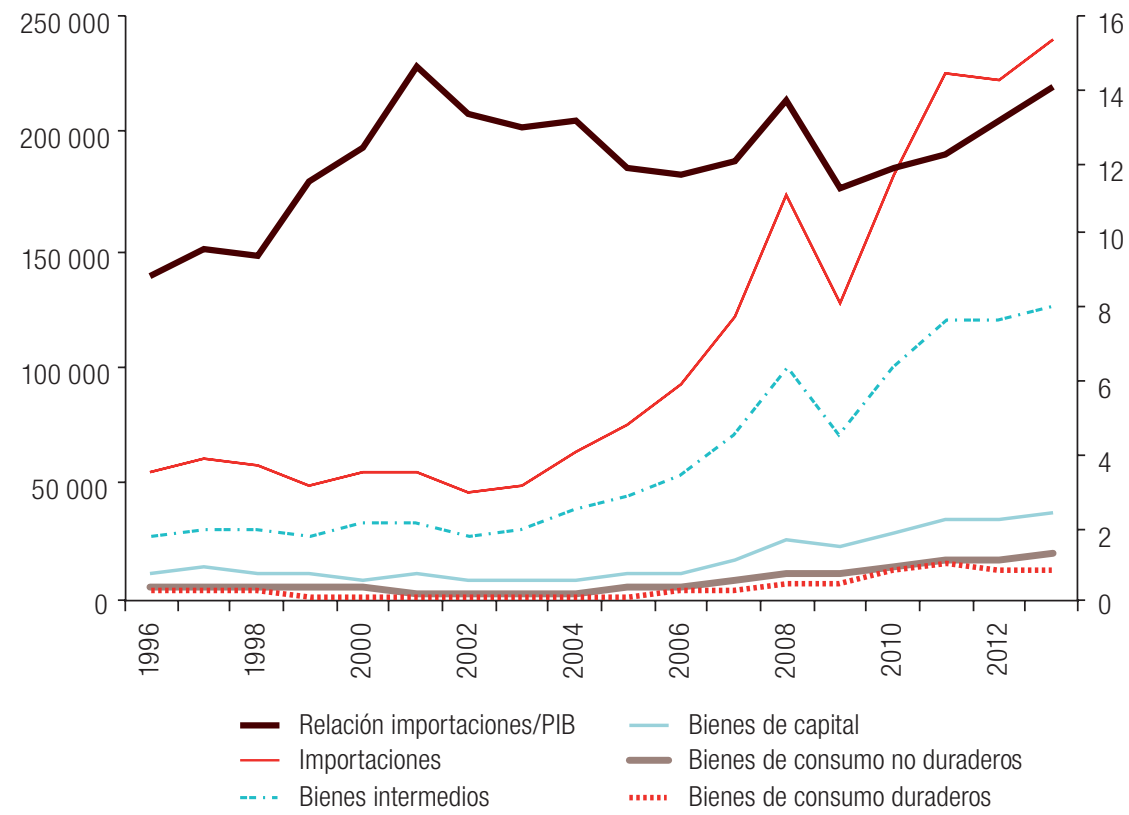

Fuente: Elaboración propia, sobre la base de datos de Ipeadata y el Sistema de Cuentas Nacionales.

Considerando este proceso de dependencia externa por el que la industria brasileña ha pasado en las últimas décadas, de manera que la parte de contenido importado en los bienes producidos internamente aumenta cada vez más, y teniendo en cuenta sus efectos negativos en el ingreso y el empleo, en este artículo se procura analizar el grado de dependencia de la industria brasileña con respecto a los insumos importados, con miras a identificar los productos de mayor necesidad (aquellos con mayor entrada en la industria del país) y su destino, es decir, los sectores de mayor peso en la demanda de importaciones.

Mediante el análisis de insumo-producto se podrán determinar cuantitativamente los sectores que, cuando se fomenta su producción, aumentan la dependencia externa de la economía, considerando sus necesidades directas e indirectas de insumos importados y la sustitución de proveedores internos por externos.

\section{Eslabones productivos industriales e importación de bienes intermedios}

Según Hirschman (1961), los eslabones industriales constituyen un importante objeto de estudio por su capacidad de impulsar el crecimiento de la economía, debido a las relaciones intersectoriales que se establecen entre las cadenas productivas. Los efectos del estímulo a la demanda de un sector, mediante las relaciones de compra y venta entre las actividades productivas, no se limitan a ese sector, sino que se sienten en otros, según sus eslabonamientos regresivos y progresivos. Para el autor, esto ocurre debido a la capacidad completiva de la industria, que se verifica cuando, al expandir su producción, una industria estimula conjuntamente la ampliación de otros sectores. 
A este respecto, es interesante mencionar las distintas perspectivas referentes a la incorporación de insumos importados en el proceso productivo industrial, o sea, cómo subsanar las carencias de la industria mediante la importación de bienes intermedios.

Ishikawa (1992) argumenta que el uso de insumos importados en el proceso productivo redundaría en beneficios para la industria. Esto se relaciona con el hecho de que la importación de insumos representa una importante fuente de transferencia de tecnología, sobre todo en los países en desarrollo (Aurea y Galvão, 1998; Lastres y Cassiolato, 2000). De esta manera, el proceso de importación representa la transferencia de conocimiento y tecnología entre naciones (Veeramani, 2009), que puede generar significativos incrementos de productividad en la actividad industrial, como se constata en los trabajos de Bonelli y Fonseca (1998), Rossi Júnior y Ferreira (1999) y Carvalho y Feijó (2000).

En un contexto trabajado más recientemente en la literatura, las cadenas globales de valor, se entiende que el acto de exportar requiere en contrapartida el de importar ${ }^{4}$. Esto queda implícito al observar que el consumo de bienes intermedios en la producción representa el 51\% del comercio internacional (Thorstensen, Ferraz y Gutierre, 2014). Teniendo esto en cuenta, las políticas que inhiben la importación de insumos tendrían efectos directos e indirectos en la capacidad del país para aumentar la complejidad tecnológica de su producción industrial destinada al mercado interno o externo, y, por lo tanto, dificultarían su inserción diferenciada en las cadenas globales de valor (Thorstensen, Ferraz y Gutierre, 2014). Así, en el contexto actual, la importación de bienes intermedios es inherente al proceso productivo y representa ganancias de competitividad a partir de una inserción internacional estratégica y diferenciada por parte del país ${ }^{5}$.

La argumentación contraria parte de la importancia de la estructura productiva para el desarrollo económico y de la manera en que la satisfacción interna de la demanda de bienes intermedios respalda la diversificación productiva y el aumento del ingreso per cápita, como señalan Marconi y Rocha (2012) a partir de Chenery, Robinson y Syrquin (1986). Esto se debe a que los bienes intermedios también se producen a partir de otros bienes intermedios, estructurando así la cadena productiva - o cadena de valor - de un bien (Marconi y Rocha, 2012, pág. 859). Teniendo esto en cuenta, a partir de Marconi y Rocha (2012) se argumenta que la continua sustitución de insumos nacionales por importados dentro del proceso productivo termina por dificultar los efectos indirectos interindustriales y obstaculizar el proceso de industrialización.

Asimismo, autores como Coutinho (1997), Morceiro (2012), Magacho (2010 y 2013) y Morceiro, Gomes y Magacho (2014) subrayan que la importación de insumos puede llevar a la ruptura de los eslabones industriales preexistentes y dificultar la formación de otros nuevos. Desde esta perspectiva, se entiende que la sustitución de proveedores internos por externos llevaría a una reducción de la capacidad de la industria de generar efectos indirectos productivos en materia de ingresos, empleo y tecnología.

Como se señala en los estudios de Marconi y Barbi (2010) y Marconi y Rocha (2012), el proceso de sustitución de insumos nacionales por importados se considera, además, como una de las causas del proceso de desindustrialización. Por último, en algunos trabajos se señalan los efectos nocivos de este proceso en la capacidad de generación de empleo de la industria (Soares, Servo y Arbache, 2001; Maia, 2001; Moreira y Najberg, 1998) y la manera en que la inserción de insumos importados

\footnotetext{
4 El fenómeno de las cadenas globales de valor consiste en la fragmentación del proceso de producción a nivel mundial. Este movimiento cobra importancia en la década de 1970, pero se profundiza de modo más prominente en la década de 2000 (UNCTAD, 2013). En este marco, las empresas dejan de actuar en todas las etapas del proceso productivo de un bien final y pasan a separarlas en distintos países, concentrándose en las actividades de mayor valor agregado. Esta estrategia permitió que las grandes empresas redujeran sus costos, a partir de la mayor incorporación de partes, piezas y componentes importados, sin que eso significase la pérdida del dominio de las principales áreas de la empresa (Gereffi, Humphrey y Sturgeon, 2005).

5 Véase Sá Porto, Canuto y Mota (2017).
} 
en la producción puede influir negativamente en la capacidad de la industria para generar de forma endógena los factores necesarios para el crecimiento económico (Magacho, 2013) ${ }^{6}$.

\section{Metodología}

\section{Matriz de insumo-producto}

Para lograr el objetivo propuesto de analizar el grado de dependencia de insumos importados en la economía brasileña, se utiliza el análisis de insumo-producto. Este modelo fue desarrollado por Leontief en la década de 1930. Este economista logró retratar la economía en un determinado período, captando las relaciones contemporáneas entre los sectores como si fueran partes de un único organismo (Guilhoto, 2004). Las relaciones económicas así sintetizadas constituyen la matriz de insumo-producto.

La matriz de insumo-producto describe la economía en términos de circulación, como un sistema integrado de flujos y transferencias de insumos y productos entre sectores. Está compuesta por el cálculo de la producción mundial y se divide en tres partes. La primera refleja la demanda intermedia, es decir, las transacciones de compra y venta entre los sectores productivos. La segunda está compuesta por el valor agregado - que comprende la remuneración de los factores, los impuestos y los subsidios que inciden en la producción - y las importaciones. La tercera, que corresponde a la demanda final, está compuesta por el consumo de las familias y del gobierno, la formación bruta de capital y las exportaciones.

Para facilitar la comprensión de la metodología, en el cuadro 1 se presenta una matriz de insumo-producto ilustrativa, en la que $X_{1}$ y $X_{2}$ son sectores productivos, $Y$ es la demanda final, $V A$ es el valor agregado, $M$ representa la parte del consumo intermedio satisfecha mediante importaciones, $T$ es el total de impuestos netos de subsidios pagados y $X$ representa el valor bruto de la producción (VBP). Las variables $x_{i j}$ representan el consumo intermedio del insumo $i$ en la producción del bien $j$. En la columna se representan los costos de las compras de insumos y en la línea los ingresos del sector originados en la venta del bien para el consumo intermedio de los demás sectores y para la demanda final.

Cuadro 1

Matriz de insumo-producto representativa

\begin{tabular}{|c|c|c|c|c|}
\hline Insumo/Producto & & & $Y$ & VBP \\
\hline$($ Costos $\downarrow / /$ ngresos $\rightarrow$ ) & $X_{1}$ & $X_{2}$ & & \\
\hline$X_{1}$ & $x_{11}$ & $x_{21}$ & $y_{1}$ & $X_{1}$ \\
\hline$X_{2}$ & $x_{12}$ & $x_{22}$ & $y_{2}$ & $X_{2}$ \\
\hline$M_{1}$ & $m_{11}$ & $m_{21}$ & & \\
\hline$M_{2}$ & $m_{12}$ & $m_{22}$ & & \\
\hline$V A$ & $v a_{1}$ & $v a_{2}$ & & \\
\hline$T$ & $t_{1}$ & $t_{2}$ & & \\
\hline$V B P$ & $X_{1}$ & $X_{2}$ & & \\
\hline
\end{tabular}

Fuente: Elaboración propia, sobre la base de R. E. Miller y P. D. Blair, Input-Output Analysis: Foundations and Extensions, Nueva York, Cambridge University Press, 2009.

6 Los trabajos aquí citados se refieren a estudios relativos al caso brasileño. 
A partir de la matriz de consumo intermedio se puede obtener la matriz de coeficientes técnicos, que está dada por:

$$
A=\left[a_{i j}\right] \text { en que } a_{i j}=\frac{x_{i j}}{x_{j}} \circ x_{i j}=a_{i j} x_{j}
$$

Para cada línea de la matriz de insumo-producto se observa entonces que:

$$
\sum_{j=1}^{n} x_{i j}+y_{i}=X_{i}=\sum_{j=1}^{n} \alpha_{i j} X_{j}+y_{i}
$$

En que $n$ es el número de sectores de la economía.

En términos matriciales, $A X+Y=X$; con algunas operaciones matriciales se obtiene:

$$
X=(I-A)^{-1} Y \quad \circ \quad X=L Y
$$

en que $I$ es una matriz identidad y $(I-A)^{-1}=L=[l i j]$ es la matriz inversa de Leontief, en que cada elemento lij, según Guilhoto (2004), representa los requisitos directos e indirectos de insumos del sector $i$ por unidad de demanda final en la producción del sector $j$. La ecuación (3) describe el modelo básico de Leontief.

Asimismo, el consumo intermedio de los $n$ sectores de la economía puede satisfacerse por medio de importaciones. A este respecto, es importante observar la relación existente entre el sector interno y el sector externo. Esta dinámica se encuentra destacada por la matriz $M$, en que cada elemento $m_{i j}$ indica el valor de la importación de bienes intermedios del sector $i$ (externo) que el sector $j$ (interno) utilizó en su proceso productivo. La matriz $M$ está en el centro del análisis de este trabajo y sus componentes se utilizan para lograr el objetivo propuesto en este estudio, como se evidencia en la próxima sección.

\section{Grado de dependencia de insumos importados}

Para el análisis de la dependencia de insumos importados se utiliza el método propuesto por Schuschny (2005), que consiste inicialmente en calcular los requisitos directos de insumos importados sectoriales. Sea $A^{m}$ la matriz de coeficientes técnicos importados dada por:

$$
A^{m}=\left[a_{i j}^{m}\right] \text { en que } a_{i j}^{m}=\frac{x_{i j}^{m}}{X_{j}}
$$

Siendo $x_{i j}^{m}$ el valor del insumo $i$ importado por el sector $j$ y $a i j^{m}$ el coeficiente que mide el valor de la importación del insumo $i$ por el sector $j$ por cada unidad monetaria producida por este sector. Así, se obtiene la matriz de importaciones totales mediante la posmultiplicación de la matriz de coeficientes de importación por la inversa de Leontief, como se indica a continuación:

$$
Q=A^{m} L \quad \circ \quad Q=[q i j]
$$

Cada elemento qij indica las importaciones directas e indirectas del insumo $i$ necesarias para generar una unidad monetaria de la producción del sector $j$. La suma de la columna $j$ de la matriz $Q\left(Q_{j}=\sum_{i=1}^{n} q_{i j}\right)$ informa el contenido total de importaciones necesario para producir internamente una unidad monetaria del sector $j$. Según Schuschny (2005), este cálculo presenta una información estructural sumamente útil, pues permite determinar las actividades cuya dependencia del resto del 
mundo es relevante en términos de demanda de importación, es decir, que dependen del exterior para incrementar su nivel de producción. A su vez, la suma de la línea $i$ de la matriz $Q\left(Q_{i}=\sum_{j=1}^{n} q_{i j}\right)$ indica la importación del insumo $i$ necesaria en caso de que la producción de todos los sectores aumente una unidad monetaria. Este indicador permite conocer los sectores del exterior de los cuales la economía tiene mayor dependencia, es decir, los más presentes en el flujo de importaciones cuando crece la producción interna.

Al comparar los indicadores descritos anteriormente con sus medias se llega a una clasificación sectorial que agrupa los sectores de acuerdo con su comportamiento como demandantes o demandados de insumos intermedios importados, como se indica en el cuadro 2.

Cuadro 2

Clasificación sectorial según la demanda de insumos intermedios importados

\begin{tabular}{ccc}
\hline & Demandantes & Poco demandantes \\
& $\left(Q_{j}>\sum_{j}^{n} Q_{j} / n\right)$ & $\left(Q_{j} \leq \sum_{j}^{n} Q_{j} / n\right)$ \\
\hline Demandados & Tipo I \\
\hline$\left(Q_{i}>\sum_{i}^{n} Q_{i} / n\right)$ & Tipo II & Tipo IV \\
\hline Poco demandados & Tipo III & \\
\hline
\end{tabular}

Fuente: Elaboración propia, sobre la base de A. R. Schuschny, "Tópicos sobre el modelo de insumo-producto: teoría y aplicaciones", serie Estudios Estadísticos y Prospectivos, № 37 (LC/L.2444-P), Santiago, Comisión Económica para América Latina y el Caribe (CEPAL), 2005.

La característica sectorial de la tipología presentada en el cuadro 2 puede describirse de la siguiente forma:

- Tipo l: cuando la producción de la economía se expande, la demanda directa e indirecta de insumos importados provenientes de estos sectores aumenta por encima de la media, pero cuando la producción de estos sectores aumenta su demanda de insumos importados es relativamente pequeña.

- Tipo Il: dependen de la importación directa e indirecta de insumos por encima de la media de la economía para incrementar su producción en una unidad monetaria y, cuando los demás sectores de la economía incrementan su producción, la importación directa e indirecta de insumos provenientes de estos sectores aumenta por encima de la media. En consecuencia, son sectores que necesitan insumos importados para producir y que atienden la demanda interna de insumos por debajo de la media de la economía. Por ese motivo, se trata de sectores que probablemente tienden a no crear muchos eslabones en el sistema productivo nacional.

- Tipo III: si bien presentan una demanda directa e indirecta de insumos importados por encima de la media de la economía, cuando los demás sectores incrementan su producción la demanda directa e indirecta de insumos importados provenientes de estos sectores es inferior a la media de la economía.

- Tipo IV: presentan una baja dependencia con respecto a la importación de insumos para aumentar su producción, de modo que los estímulos a los sectores industriales con esta clasificación son apropiados por el sector interno. Asimismo, son sectores poco 
demandados, de manera que cuando se incrementa la producción de la economía, la demanda directa e indirecta de importación de insumos provenientes de estos sectores es inferior a la media de todos los sectores.

Se entiende aquí que los sectores clasificados como tipo II o tipo III son aquellos que tienden a aumentar la dependencia externa del país, debido a que su producción impulsa directa e indirectamente la importación por medio de su demanda intermedia. Estos sectores dependen de la importación de insumos para incrementar su producción y, por lo tanto, son aquellos que generan un menor valor agregado internamente, con repercusiones negativas en la cadena productiva nacional.

\section{Base de datos}

Se utilizan las matrices de insumo-producto de los años 2000 a 2014 disponibles en la Base de Datos Mundial de Insumos-Productos (WIOD). Las matrices de insumo-producto y de importación de insumos intermedios están desagregadas en 56 sectores, 20 de los cuales pertenecen a la industria. Esto permite un análisis detallado de la dependencia externa de la producción industrial nacional. Los datos contenidos en las matrices se miden en millones de dólares a precios del año corriente.

\section{Discusión de resultados}

En esta sección se discuten los resultados obtenidos al aplicar la metodología explicada anteriormente. Para una mejor comprensión se utiliza la clasificación de Pavitt (1984) y la Organización de Cooperación y Desarrollo Económicos (OCDE) (2005), que agrupa a los sectores de acuerdo con su tipo de industria o tecnología. Así, los sectores se reúnen en grupos con características industriales similares, de modo que la discusión se subdivide de la siguiente forma: industria intensiva en recursos naturales, industria intensiva en escala, industria basada en la ciencia, industria intensiva en trabajo e industria con tecnología diferenciada.

\section{Industria intensiva en recursos naturales}

En una discusión reciente en la literatura científica se evidencia un cambio estructural en la industria brasileña que se intensificó a partir de las medidas de apertura económica de la década de 1990. Algunos autores, como Nassif (2008) y Oreiro y Feijó (2010), mostraron que en el Brasil hubo una reorientación de la producción industrial hacia la industria intensiva en recursos naturales, que asumió un papel clave en el desempeño de la economía nacional. Así, el análisis de su dependencia de la importación de insumos cobra relevancia para identificar los sectores que estimulan directa e indirectamente las importaciones al aumentar su producción y, de ese modo, establecer si los estímulos generados en esta industria son apropiados externamente.

Los sectores que pertenecen a la industria intensiva en recursos naturales se detallan en el cuadro 3, en el que se indica su clasificación de acuerdo con el grado de dependencia externa. En primer lugar, se observa que, si bien esta industria se ha destacado en la economía debido a su desempeño exportador, en general los sectores intensivos en recursos naturales demandan insumos importados directa e indirectamente por encima de la media de la economía para incrementar su producción. 


\section{Cuadro 3}

Brasil: clasificación del grado de dependencia de insumos importados de la industria intensiva en recursos naturales

\begin{tabular}{|c|c|c|c|c|c|c|c|c|c|c|c|c|c|c|c|}
\hline Sectores/Año & 2000 & 2001 & 2002 & 2003 & 2004 & 2005 & 2006 & 2007 & 2008 & 2009 & 2010 & 2011 & 2012 & 2013 & 2014 \\
\hline Industria extractiva & $\|$ & $\|$ & $\|$ & $\|$ & $\|$ & $\|$ & I & $\|$ & I & $\|$ & $\|$ & $\|$ & I & I & I \\
\hline $\begin{array}{l}\text { Productos alimenticios, } \\
\text { bebidas y tabaco }\end{array}$ & III & III & III & III & III & III & III & III & III & III & III & III & III & III & III \\
\hline $\begin{array}{l}\text { Coque y refinación } \\
\text { de petróleo }\end{array}$ & $\|$ & $\|$ & $\|$ & $\|$ & $\|$ & $\|$ & $\|$ & $\|$ & $\|$ & $\|$ & $\|$ & $\|$ & $\|$ & $\|$ & $\|$ \\
\hline $\begin{array}{l}\text { Otros productos } \\
\text { minerales no metálicos }\end{array}$ & III & III & III & III & III & III & III & III & III & III & $\|$ & III & III & III & III \\
\hline $\begin{array}{l}\text { Productos metálicos } \\
\text { (excepto máquinas } \\
\text { y equipos) }\end{array}$ & $\|$ & III & $\|$ & $\|$ & $\|$ & III & III & III & III & III & III & III & III & $\|$ & $\|$ \\
\hline
\end{tabular}

Fuente: Elaboración propia, sobre la base de información de la Base de Datos Mundial de Insumos-Productos (WIOD).

En el cuadro 3 se observa que, entre 2000 y 2011, la industria extractiva se clasificó en general como tipo II, ya que la producción del sector demanda insumos importados por encima de la media y la economía depende de la importación de insumos provenientes de este sector por encima de la media para incrementar su producción. No obstante, a partir de 2012 la industria extractiva pasa a clasificarse como tipo I, por lo que se puede decir que su dependencia del sector externo se redujo relativamente durante este período. En el gráfico 2 puede observarse que la demanda directa e indirecta de insumos importados de la industria extractiva disminuye ligeramente por debajo de la media de la economía en los últimos tres años.

Gráfico 2

Brasil: valor de la demanda directa e indirecta de insumos importados de la industria intensiva en recursos naturales por cada dólar producido por los sectores, 2000-2014

(En dólares)

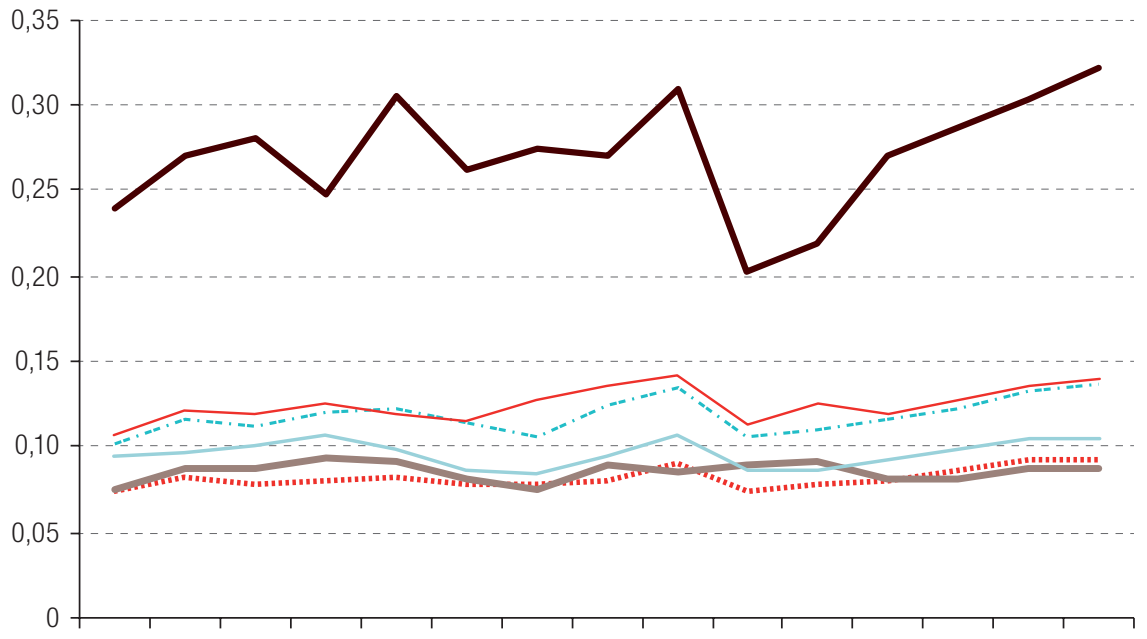

200020012002200320042005200620072008200920102011201220132014

- Fabricación de coque y refinación de petróleo

— Fabricación de productos metálicos (excepto máquinas y equipos)

-- - - Fabricación de otros productos minerales no metálicos

_ Fabricación de productos alimenticios, bebidas y tabaco

- Industria extractiva

...... Media

Fuente: Elaboración propia, sobre la base de información de la Base de Datos Mundial de Insumos-Productos (WIOD). 
No obstante, en el gráfico 3 resulta evidente que la economía presenta una considerable dependencia de la importación de insumos provenientes de la industria extractiva y que esta se mantiene elevada a lo largo de los años. Mientras el aumento de la producción de los demás sectores de la economía en una unidad monetaria se traducía en un requisito directo e indirecto de importación de este sector de 0,24 dólares en 2000, esa cifra aumentó a 0,58 dólares en 2014. Cabe subrayar que, en 2014, los sectores más dependientes de la importación de este tipo de insumos fueron los siguientes: fabricación de coque y refinación de petróleo (responsable del $27 \%$ del resultado obtenido ese año), fabricación de metales básicos, fabricación de otros productos minerales no metálicos y fabricación de químicos y productos químicos (fabricación de sustancias y productos químicos).

\section{Gráfico 3}

Brasil: valor de la demanda directa e indirecta de insumos importados de la industria intensiva en recursos naturales por cada dólar producido en la economía, 2000-2014

(En dólares)

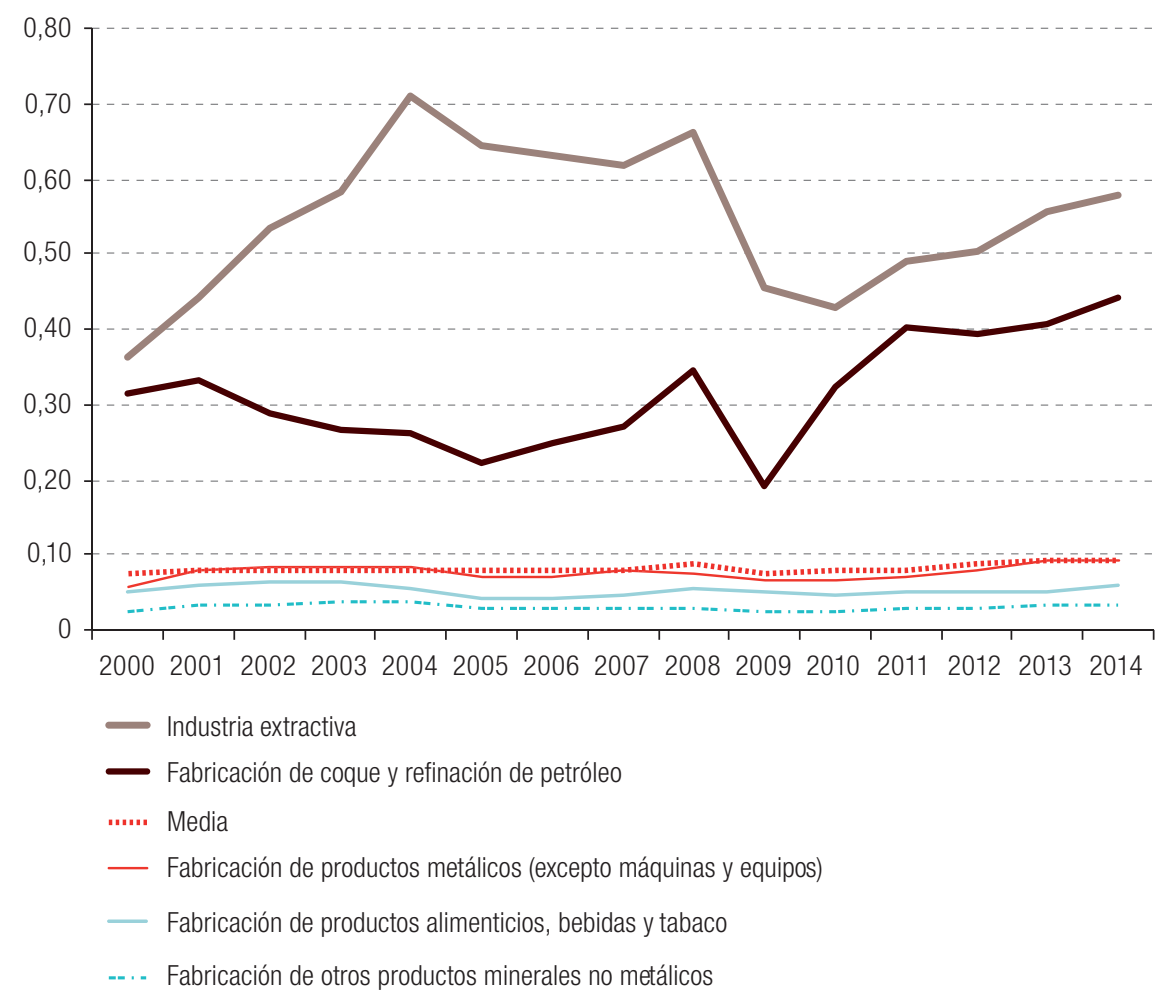

Fuente: Elaboración propia, sobre la base de información de la Base de Datos Mundial de Insumos-Productos (WIOD).

El sector de coque y refinación de petróleo se destacó en relación con los demás sectores estudiados debido a su elevada dependencia externa. Como se observó en el cuadro 3, este sector fue clasificado como tipo II, por entenderse que presenta requisitos de importación de bienes intermedios superiores a la media de la economía y también corresponde a insumos de cuya importación depende la economía para aumentar la producción.

Al analizar el sector de coque y refinación de petróleo por separado en la matriz $Q$, se observa que el principal insumo importado por este durante todo el período de 2000 a 2014 proviene de la industria extractiva, que en media representa el $40 \%$ de sus importaciones. De esta forma, se constata que el sector de refinación de petróleo presenta dependencia de un insumo que está estrictamente relacionado con su producto final, pues el sector de extracción de petróleo y gas se encuentra dentro de la industria extractiva. 
En el gráfico 2 se aprecia que, entre los sectores aquí analizados, el sector de coque y refinación de petróleo es el que presenta mayores requisitos de importación. En el período estudiado, ese sector importó directa e indirectamente una media de cerca de 0,27 dólares por cada dólar producido y en 2014 alcanzó un valor de 0,32 dólares. En forma análoga, en el gráfico 3 se verifica que, cuando la producción de los demás sectores de la economía aumenta un dólar, la demanda directa e indirecta de importación ligada a este sector corresponde a una media de 0,31 dólares en el período analizado.

Asimismo, se observa que los sectores que presentaron mayor dependencia de la importación de insumos del sector de coque y refinación de petróleo durante el período 2000-2014 son, respectivamente: coque y refinación de petróleo, transporte aéreo, sustancias y productos químicos, transporte terrestre y fabricación de plástico y caucho.

El sector de alimentos, bebidas y tabaco mostró continuidad en lo que respecta a su clasificación como tipo III. Como se puede ver en el gráfico 2, el sector presenta una dependencia externa relacionada con la importación de insumos y, de hecho, registró una media de importación de 0,10 dólares por dólar producido en el período examinado. Sin embargo, la demanda directa e indirecta de la economía de insumos importados provenientes de este sector fue, en general, inferior a la media de la economía.

El sector de otros productos minerales no metálicos fue en general clasificado como tipo III, es decir, como un sector cuya producción requiere directa e indirectamente insumos importados por encima de la media de la economía, como se evidencia en el gráfico 2. No obstante, cuando los demás sectores de la economía incrementan su producción, su dependencia externa en relación con el sector de otros productos minerales no metálicos es baja, como se puede ver en el gráfico 3.

Por último, el sector de fabricación de productos metálicos fue considerado como tipo II y tipo III durante el período analizado, dado que su producción depende de las importaciones y, a su vez, la economía presenta una dependencia externa de los insumos provenientes de este sector para realizar sus actividades productivas. De esta forma, el estímulo a la fabricación de productos metálicos se asocia, en contrapartida, con el aumento de la entrada de importaciones en el país.

\section{Industria intensiva en escala}

Los sectores pertenecientes a la industria intensiva en escala se detallan en el cuadro 4. En este es posible observar que la producción de la industria intensiva en escala es muy dependiente de la importación de insumos intermedios. Esto resulta evidente pues en general esta industria fue clasificada como tipo II (demandante y demandada) y tipo III (demandante y poco demandada).

El sector de fabricación de papel y productos de papel presentó un cambio en su clasificación a partir de 2007, cuando dejó de considerarse como de tipo II y pasó a ser de tipo III, como se puede observar en el cuadro 4. Esto a su vez significa que, para realizar sus actividades productivas, los demás sectores fueron reduciendo su dependencia externa del sector de fabricación de papel y productos de papel a lo largo del tiempo. 


\section{Cuadro 4}

Brasil: clasificación del grado de dependencia de insumos importados de la industria intensiva en escala

\begin{tabular}{|c|c|c|c|c|c|c|c|c|c|c|c|c|c|c|c|}
\hline Sectores/Año & 2000 & 2001 & 2002 & 2003 & 2004 & 2005 & 2006 & 2007 & 2008 & 2009 & 2010 & 2011 & 2012 & 2013 & 2014 \\
\hline $\begin{array}{l}\text { Papel y productos } \\
\text { de papel }\end{array}$ & $\|$ & $\|$ & $\|$ & $\|$ & $\|$ & $\|$ & $\|$ & III & III & III & III & III & III & III & III \\
\hline $\begin{array}{l}\text { Impresión y } \\
\text { reproducción } \\
\text { de medios }\end{array}$ & III & III & III & III & III & III & III & III & III & III & III & III & III & III & III \\
\hline $\begin{array}{l}\text { Sustancias y } \\
\text { productos químicos }\end{array}$ & $\|$ & $\|$ & $\|$ & $\|$ & $\|$ & $\|$ & $\|$ & $\|$ & $\|$ & $\|$ & $\|$ & $\|$ & $\|$ & $\|$ & $\|$ \\
\hline $\begin{array}{l}\text { Caucho y productos } \\
\text { plásticos }\end{array}$ & $\|$ & $\|$ & $\|$ & $\|$ & $\|$ & $\|$ & $\|$ & $\|$ & $\|$ & $\|$ & $\|$ & $\|$ & $\|$ & $\|$ & $\|$ \\
\hline Metales básicos & $\|$ & $\|$ & $\|$ & $\|$ & $\|$ & $\|$ & $\|$ & $\|$ & $\|$ & $\|$ & $\|$ & $\|$ & $\|$ & $\|$ & $\|$ \\
\hline Vehículos y afines & $\|$ & $\|$ & $\|$ & $\|$ & $\|$ & $\|$ & $\|$ & $\|$ & $\|$ & $\|$ & $\|$ & $\|$ & $\|$ & $\|$ & $\|$ \\
\hline $\begin{array}{l}\text { Otros equipos } \\
\text { de transporte }\end{array}$ & III & $\|$ & III & III & III & $\|$ & $\|$ & $\|$ & $\|$ & $\|$ & $\|$ & $\|$ & $\|$ & $\|$ & $\|$ \\
\hline
\end{tabular}

Fuente: Elaboración propia, sobre la base de información de la Base de Datos Mundial de Insumos-Productos (WIOD).

Según Montebello y Bacha (2011), las empresas del sector de celulosa y papel en el Brasil están verticalizadas, operan en diversas etapas del proceso productivo y su principal ventaja comparativa está en la producción de celulosa, debido a la alta producción de madera de bosques plantados en el país. Esos autores señalan además que la producción del sector de celulosa se ha expandido significativamente en los últimos años para atender el mercado externo. Es interesante que, según los autores, no obstante el sector de celulosa sea intensivo en capital, por cada empleo directo generado se crean indirectamente otros cinco en función de las actividades interrelacionadas con este sector. Así, cabe subrayar que el cambio de clasificación de esta industria está vinculado con su desarrollo interno en la creación de nuevas empresas ligadas a este sector, que a su vez posibilitó su integración en fases ulteriores de la cadena productiva nacional y redujo la dependencia externa de la economía nacional en relación con el sector de papel y celulosa.

En general, el sector de impresión y reproducción de medios fue clasificado como tipo III, es decir que, para incrementar su producción, demanda insumos importados por encima de la media de la economía. Si bien el sector presentó una media de importación de insumos de 0,11 dólares por cada dólar producido, en el gráfico 4 se puede observar que mantuvo su requisito directo e indirecto de insumos importados relativamente constante en el período estudiado, de manera que - en general - no sustituyó a los proveedores internos por externos a lo largo del tiempo. Al analizar la dependencia externa de la economía brasileña en relación con este sector se observa que esta es próxima a cero (véase el gráfico 5). 


\section{Gráfico 4}

Brasil: valor de la demanda directa e indirecta de insumos importados de la industria intensiva en escala por cada dólar producido por los sectores, 2000-2014

(En dólares)

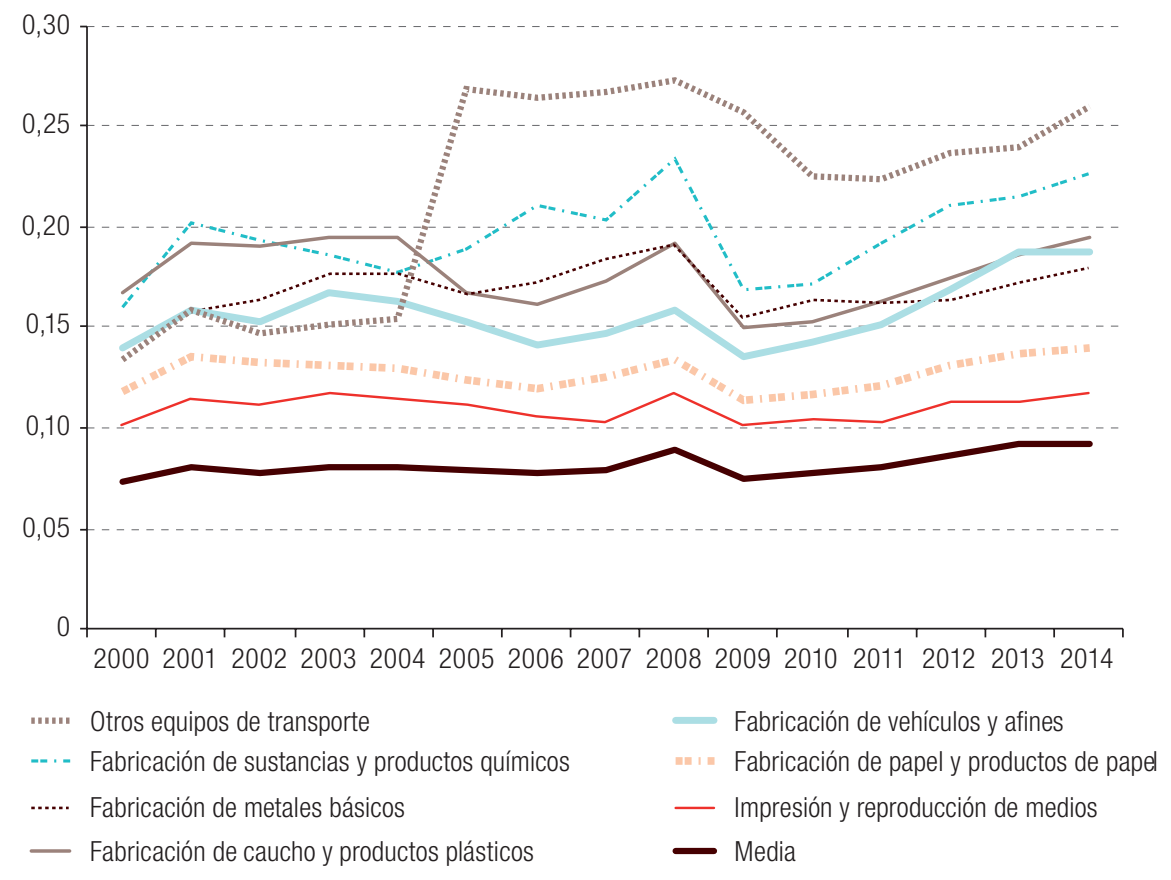

Fuente: Elaboración propia, sobre la base de información de la Base de Datos Mundial de Insumos-Productos (WIOD).

\section{Gráfico 5}

Brasil: valor de la demanda directa e indirecta de insumos importados de la industria intensiva en escala por cada dólar producido en la economía, 2000-2014 (En dólares)

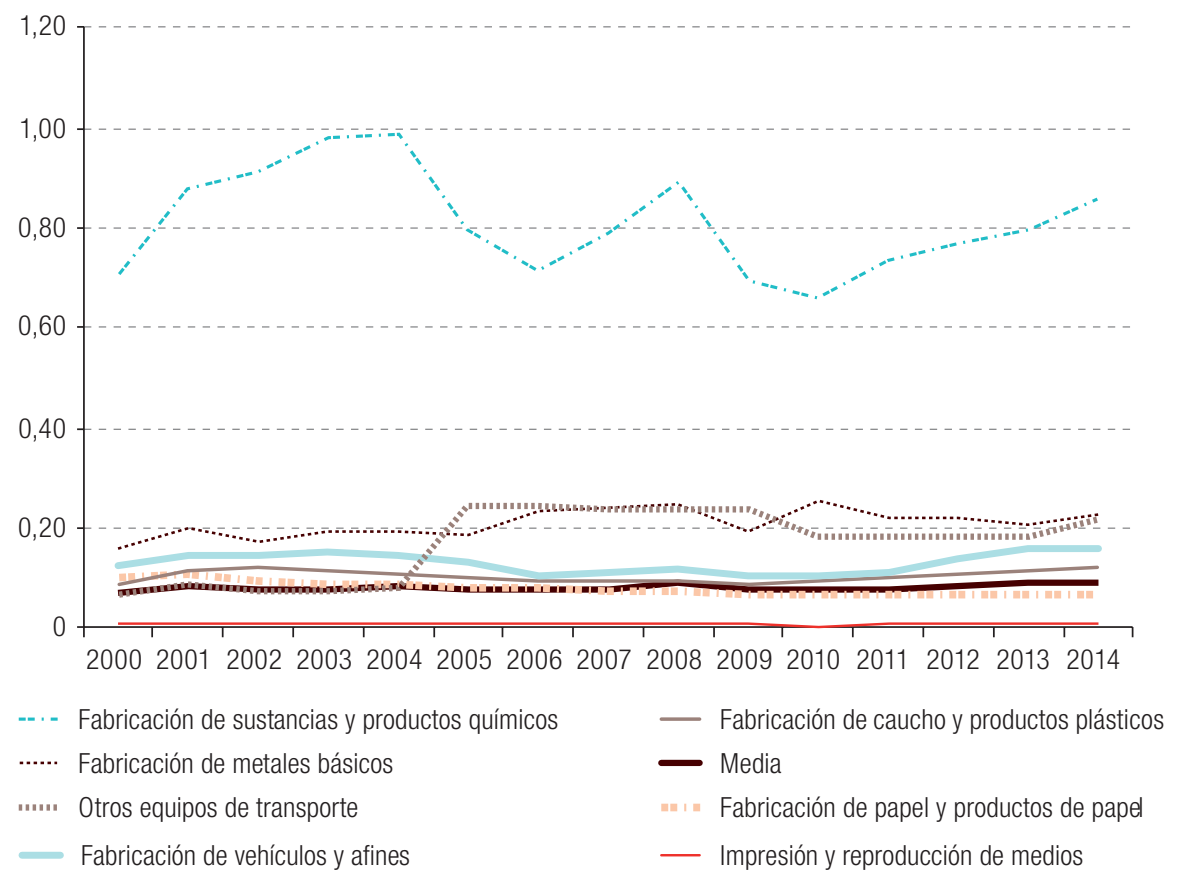

Fuente: Elaboración propia, sobre la base de información de la Base de Datos Mundial de Insumos-Productos (WIOD). 
Entre los sectores aquí estudiados, la mayor dependencia externa de la economía se registra en el sector de sustancias y productos químicos. Cuando la producción de la economía se incrementa en un dólar, la necesidad directa e indirecta de insumos importados provenientes del sector de sustancias y productos químicos alcanza una media de 0,81 dólares. Los sectores que presentaron la mayor dependencia externa en relación con la importación de insumos de sustancias y productos químicos fueron: sustancias y productos químicos, fabricación de caucho y productos plásticos, producción animal y vegetal y actividades de servicios relacionados, fabricación de papel y productos de papel y productos farmacéuticos. Asimismo, la producción de este sector demanda en media 0,20 dólares por dólar producido y casi la mitad de ese valor está relacionada con el propio sector de sustancias y productos químicos, de manera que los efectos indirectos generados por este sector dejan en gran medida de ser apropiados por la economía nacional.

En el cuadro 4 se puede observar que el sector de caucho y productos plásticos y el sector de metales básicos fueron clasificados como tipo II a lo largo de los años estudiados. Estos sectores presentaron una media de importación de insumos de 0,18 y 0,17 dólares para cada dólar producido, respectivamente. Así, cuando estos sectores aumentan su producción, estimulan la entrada de importaciones en el país. Cabe destacar que la principal dependencia del sector de caucho y productos plásticos corresponde a la importación de sustancias y productos químicos, que representa más del $52 \%$ de su importación directa e indirecta, mientras el sector de metales básicos presenta un mayor requisito de importaciones provenientes de la industria extractiva (35\%).

En general, el sector de vehículos y afines y el de otros equipos de transporte fueron clasificados como tipo II en cuanto a su dependencia externa. Esto significa que dependen de la importación de insumos para producir y que la economía demanda insumos importados provenientes de estos sectores, como se evidencia en los gráficos 4 y 5 . Estos revelan que ambos sectores presentan requisitos directos e indirectos de insumos por encima de la media de la economía y también que al estimular la economía, esta demanda insumos importados provenientes de estos sectores por encima de la media. Como se observa en el gráfico 4, el sector de vehículos y afines incrementa de modo gradual su demanda directa e indirecta de insumos importados durante el período analizado y presenta una media de 0,16 dólares por dólar producido. Este valor aumenta a 0,22 dólares en el caso del sector de otros equipos de transporte. Es interesante señalar que los principales insumos demandados por estos sectores provienen de proveedores externos vinculados con la producción de vehículos y otros y otros equipos de transporte, respectivamente.

Al analizar la industria brasileña intensiva en escala se aprecia que los efectos indirectos intersectoriales generados por esta son, en gran parte, apropiados por el sector externo. Esto queda de manifiesto en los gráficos presentados, en los cuales se observa que todos los sectores que componen esta industria demandan de forma directa e indirecta insumos importados por encima de la media de la economía. Es decir, que el aumento de la producción de estos sectores está inexorablemente ligado al incremento de la entrada de importaciones en el país.

\section{Industria basada en la ciencia}

La industria basada en la ciencia, caracterizada por su alto contenido tecnológico, está compuesta únicamente por la industria farmacéutica y la fabricación de productos farmacéuticos. En el cuadro 5 se puede observar que, en general, este sector fue clasificado como tipo III, es decir, fue considerado un sector demandante de insumos importados. En consecuencia, se puede afirmar que al aumentar la producción de la industria basada en la ciencia se estimulan directa e indirectamente las importaciones. 


\section{Cuadro 5}

Brasil: clasificación del grado de dependencia de insumos importados de la industria basada en la ciencia

\begin{tabular}{|c|c|c|c|c|c|c|c|c|c|c|c|c|c|c|c|}
\hline Sector/Año & 2000 & 2001 & 2002 & 2003 & 2004 & 2005 & 2006 & 2007 & 2008 & 2009 & 2010 & 2011 & 2012 & 2013 & 2014 \\
\hline $\begin{array}{l}\text { Industria } \\
\text { farmacéutica } \\
\text { y fabricación } \\
\text { de productos } \\
\text { farmacéuticos }\end{array}$ & IV & |II & III & III & III & IV & IV & III & III & III & III & III & III & III & III \\
\hline
\end{tabular}

Fuente: Elaboración propia, sobre la base de información de la Base de Datos Mundial de Insumos-Productos (WIOD).

En general, como se muestra en el gráfico 6, la demanda directa e indirecta de insumos importados de la industria basada en la ciencia supera la media de la economía y su dependencia externa aumenta gradualmente a lo largo del período examinado. De esto se deduce que probablemente en este sector se ha sustituido a los proveedores internos a lo largo del tiempo. Se observa que, entre 2000 y 2014 , este sector demandó una media de 0,08 dólares de importación de insumos por dólar producido.

Gráfico 6

Brasil: valor de la demanda directa e indirecta de insumos importados de la industria basada en la ciencia por cada dólar producido por los sectores, 2000-2014

(En dólares)

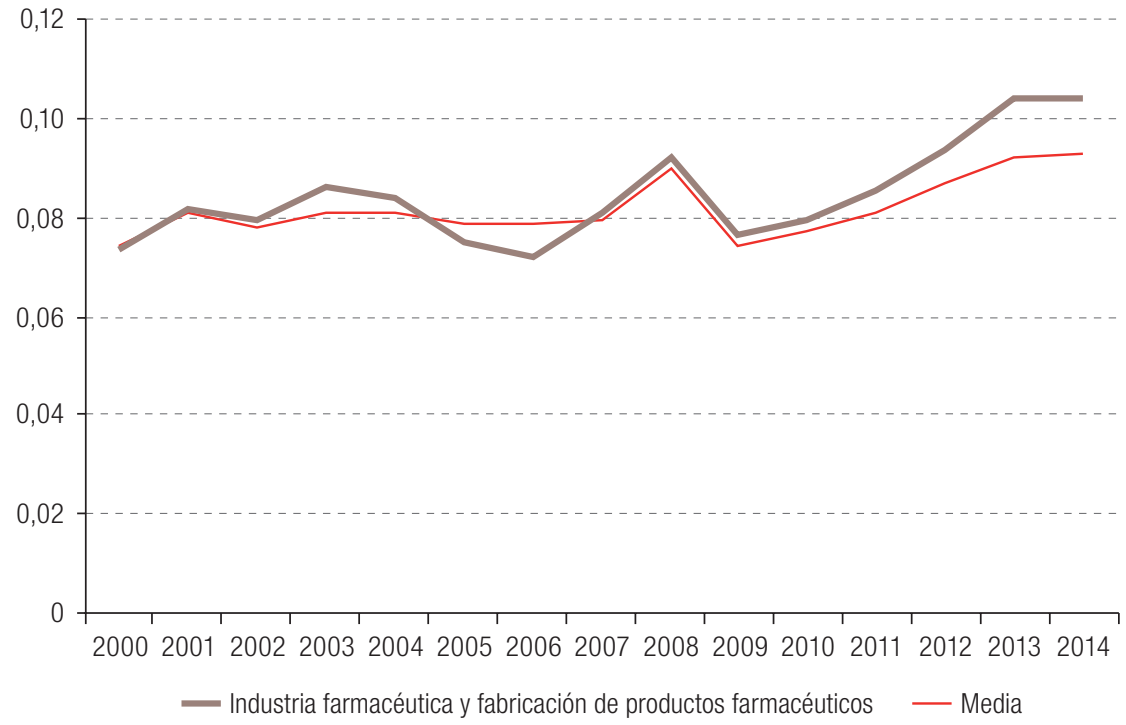

Fuente: Elaboración propia, sobre la base de información de la Base de Datos Mundial de Insumos-Productos (WIOD).

Como la industria basada en la ciencia fue considerada en general como de tipo III (es decir, un sector poco demandado por la economía), el valor de la demanda directa e indirecta de insumos importados es inferior a la media, como se puede observar en el gráfico 7. Así, la economía presenta una baja dependencia de insumos importados provenientes de este sector, de manera que, cuando su producción aumenta las importaciones provenientes de la industria farmacéutica y la fabricación de productos farmacéuticos son bajas. 


\section{Gráfico 7}

Brasil: valor de la demanda directa e indirecta de insumos importados de la industria basada en la ciencia por cada dólar producido en la economía, 2000-2014

(En dólares)

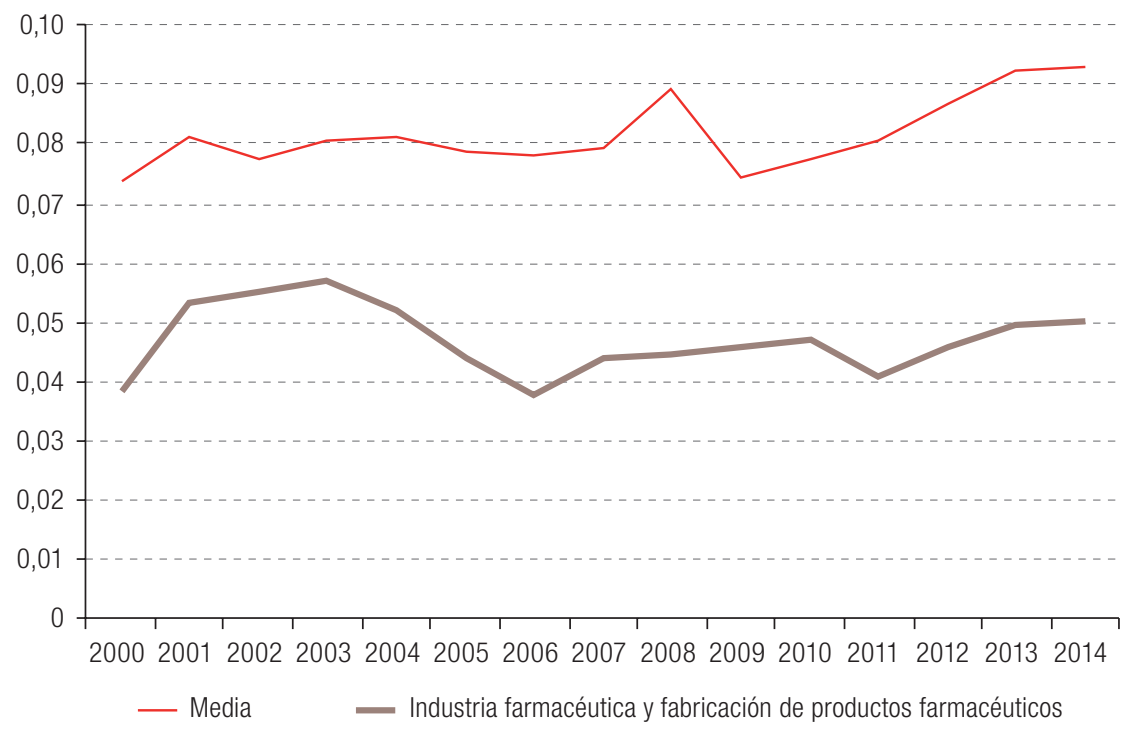

Fuente: Elaboración propia, sobre la base de información de la Base de Datos Mundial de Insumos-Productos (WIOD).

Brógio (2002) argumenta que las empresas farmacéuticas de capital nacional presentan fragilidades, en la medida en que en la atención del mercado de consumo interno brasileño predomina el capital extranjero. Desde esta perspectiva, la autora constata que las empresas que actúan en el Brasil presentan bajos niveles de integración y que esto se relacionaría con el hecho de que las grandes empresas mantienen centralizado en sus países de origen el segmento productor de insumos, lo que da lugar a una fuerte dependencia de las importaciones provenientes de esos países (Brógio, 2002, pág. 115). Canchumani (2009) explica que las empresas nacionales y de capital extranjero que actúan en el país se dedican a las últimas etapas del proceso productivo - la formulación y comercialización de medicamentos - y presentan un alto grado de dependencia en relación con las etapas anteriores que se desarrollan en la matriz, de manera que el proceso productivo de la industria farmacéutica está vinculado al aumento de las importaciones.

\section{Industria intensiva en mano de obra}

Los sectores que componen la industria intensiva en mano de obra se detallan en el cuadro 6. En primer lugar, se observa que el Brasil no presenta dependencia de la importación de bienes intermedios provenientes de esta industria, pues cuando la producción de la economía se incrementa, las importaciones de insumos provenientes de estos sectores no aumentan de forma significativa, como se puede observar en el gráfico 8. Esto se refleja en la clasificación de estos sectores como tipo IV o III, como se puede apreciar en el cuadro 6. 


\section{Gráfico 8}

Brasil: valor de la demanda directa e indirecta de insumos importados de la industria intensiva en mano de obra por cada dólar producido por los sectores, 2000-2014

(En dólares)

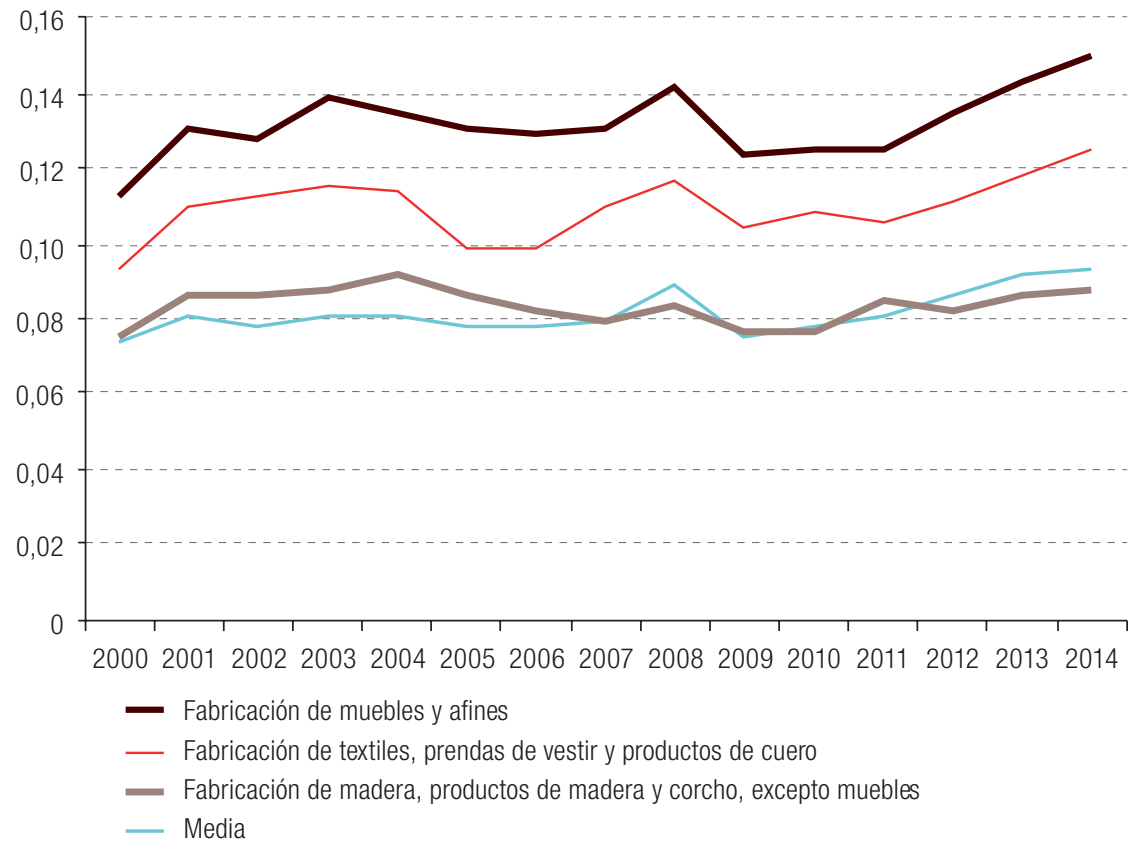

Fuente: Elaboración propia, sobre la base de información de la Base de Datos Mundial de Insumos-Productos (WIOD).

\section{Cuadro 6}

Brasil: clasificación del grado de dependencia de insumos importados de la industria intensiva en mano de obra

\begin{tabular}{|c|c|c|c|c|c|c|c|c|c|c|c|c|c|c|c|}
\hline Sectores/Año & 2000 & 2001 & 2002 & 2003 & 2004 & 2005 & 2006 & 2007 & 2008 & 2009 & 2010 & 2011 & 2012 & 2013 & 2014 \\
\hline $\begin{array}{l}\text { Textil, prendas de } \\
\text { vestir y productos } \\
\text { de cuero }\end{array}$ & III & III & III & III & III & III & III & III & III & III & $\|$ & III & III & III & III \\
\hline $\begin{array}{l}\text { Madera, productos } \\
\text { de madera y corcho, } \\
\text { excepto muebles }\end{array}$ & IV & III & III & III & III & III & III & III & IV & III & IV & III & IV & IV & IV \\
\hline Muebles y otros & III & III & ||| & III & III & III & |II & III & ||| & III & |II & |II & |II & |II & III \\
\hline
\end{tabular}

Fuente: Elaboración propia, sobre la base de información de la Base de Datos Mundial de Insumos-Productos (WIOD).

En general, el sector de madera, productos de madera y corcho (excepto muebles) fue clasificado como tipo IV, es decir como poco demandante. En consecuencia, su demanda de insumos importados es inferior a la media de la economía y, además, los bienes intermedios externos de este sector fueron poco demandados por los demás sectores, como se muestra en el gráfico 9. Así, se puede afirmar que el fomento de la producción en este sector tendría pocas repercusiones en la importación, de modo que los efectos indirectos generados por este serían apropiados por la cadena productiva nacional. 


\section{Gráfico 9}

Brasil: valor de la demanda directa e indirecta de insumos importados de la industria intensiva en mano de obra por cada dólar producido en la economía, 2000-2014

(En dólares)

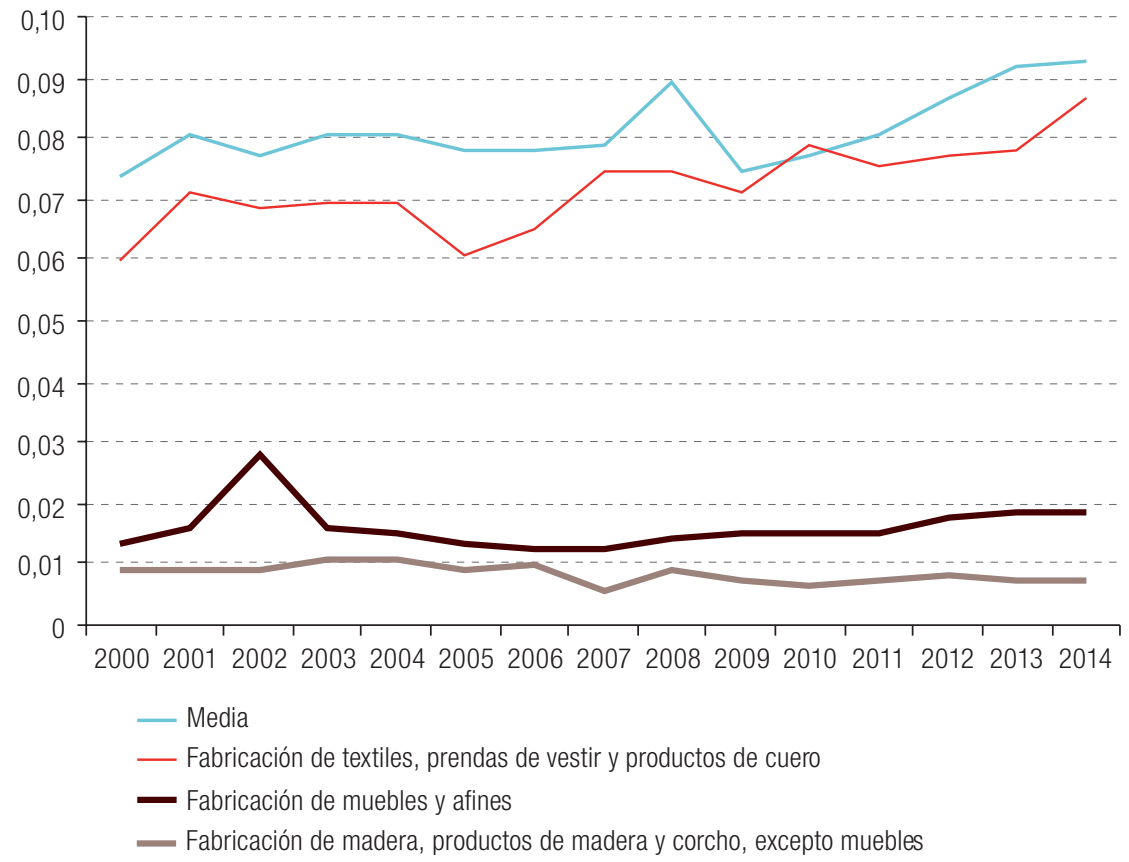

Fuente: Elaboración propia, sobre la base de información de la Base de Datos Mundial de Insumos-Productos (WIOD).

En el cuadro 6 se observa que el sector textil, de prendas de vestir y productos de cuero fue clasificado como tipo III durante todo el período, de manera que al incrementar la producción su demanda directa e indirecta de insumos importados fue superior a la media de la economía. En el período examinado, la media de importación de bienes intermedios fue de alrededor de 0,11 dólares por dólar producido y gradualmente se sustituyeron los proveedores internos por externos, como se muestra en el gráfico 8.

De acuerdo con Gorini y Siqueira (1997), el saldo de la balanza comercial brasileña relacionado con el sector textil resultó perjudicado por la apertura comercial. Este saldo presentaba una tendencia decreciente desde 1992 y en 1996 llegó a un déficit de 1.016.866 dólares, no tanto por una caída de las exportaciones sino por un aumento significativo de las importaciones, especialmente de productos a partir de fibras artificiales o sintéticas (incluidos los textiles no tejidos) y algodón (Gorini y Siqueira, 1997, pág. 3). Estos autores enumeraran diversos motivos para el aumento de la participación del algodón en la estructura de importación de la industria textil, entre ellos la reducción de las cuotas de importación, los diferentes plazos de pago de los proveedores externos con respecto a los internos, el aumento de la oferta mundial y la consecuente reducción de los precios y, por último, el hecho de que en algunos países como los Estados Unidos el producto recibió subsidios.

De acuerdo con Kon y Coan (2009), la liberalización comercial posibilitó e intensificó la entrada de importaciones. Esta exacerbó la competencia, lo que a su vez causó la quiebra de numerosas empresas de ese sector. Sin embargo, tras el impacto de las políticas implementadas en la década de 1990 en la industria textil, se buscó llevar a cabo una reestructuración productiva de este sector para obtener ganancias de competitividad y restablecerse, con miras a atender los mercados interno y externo. La innovación del proceso productivo fue muy acentuada en el caso de la industria textil, porque requirió la modernización del parque industrial textil mediante la informatización de la 
producción (Kon y Coan, 2009, pág. 21). Según los autores, en la década de 2000 el Programa de Reestructuración del Sector Textil, del Banco Nacional de Desarrollo Económico y Social (BNDES), permitió aumentar la productividad y amplió la capacidad productiva de este sector mediante ingentes inversiones, no solo en la formación de capital físico, sino también en tecnología e innovación. No obstante, otro desafío enfrentado por este sector en la década de 2000 se relaciona con la alta competitividad china en el escenario internacional, como se indica en el trabajo de Rangel, Silva y Costa (2010).

Por último, durante el período estudiado el sector de fabricación de muebles y afines fue considerado como un sector demandante y, en consecuencia, clasificado como tipo III. En el gráfico 8 se observa que, entre 2000 y 2014, este sector sustituyó proveedores internos por externos, en la medida en que al inicio de la serie la demanda directa e indirecta de insumos importados asumía el valor de 0,11 dólares por dólar producido, mientras que en el último año este valor aumentó a 0,15 dólares.

\section{Industria con tecnología diferenciada}

Los resultados de la clasificación de los sectores pertenecientes a la industria con tecnología diferenciada se detallan en el cuadro 7. Con excepción del sector de reparación e instalación de máquinas y equipos, esta industria es considerada como de tipo II, de manera que, para aumentar su nivel de producción, los sectores presentan requisitos directos e indirectos de insumos importados por encima de la media de la economía y, en forma análoga, la producción de la economía depende de la importación de insumos provenientes de estos sectores.

\section{Cuadro 7}

Brasil: clasificación del grado de dependencia de insumos importados de la industria con tecnología diferenciada

\begin{tabular}{|c|c|c|c|c|c|c|c|c|c|c|c|c|c|c|c|}
\hline Sectores/Año & 2000 & 2001 & 2002 & 2003 & 2004 & 2005 & 2006 & 2007 & 2008 & 2009 & 2010 & 2011 & 2012 & 2013 & 2014 \\
\hline $\begin{array}{l}\text { Equipos de informática, } \\
\text { productos electrónicos } \\
\text { y ópticos }\end{array}$ & $\|$ & $\|$ & ॥ & $\|$ & $\|$ & $\|$ & $\|$ & $\|$ & ॥ & $\|$ & $\|$ & $\|$ & $\|$ & $\|$ & $\|$ \\
\hline Equipos eléctricos & $\|$ & $\|$ & $\|$ & $\|$ & $\|$ & $\|$ & $\|$ & $\|$ & $\|$ & $\|$ & $\|$ & $\|$ & $\|$ & $\|$ & $\|$ \\
\hline $\begin{array}{l}\text { Máquinas y equipos } \\
\text { y no clasificados } \\
\text { en otra parte }\end{array}$ & $\|$ & $\|$ & $\|$ & $\|$ & $\|$ & $\|$ & $\|$ & $\|$ & $\|$ & $\|$ & $\|$ & $\|$ & $\|$ & $\|$ & $\|$ \\
\hline $\begin{array}{l}\text { Reparación e } \\
\text { instalación de } \\
\text { máquinas y equipos }\end{array}$ & IV & IV & IV & IV & IV & IV & IV & IV & IV & IV & IV & IV & I & I & I \\
\hline
\end{tabular}

Fuente: Elaboración propia, sobre la base de información de la Base de Datos Mundial de Insumos-Productos (WIOD).

Durante todo el período estudiado, el sector de equipos de informática, productos electrónicos y ópticos se clasificó como tipo II, es decir, como un sector demandante y demandado. Como se muestra en el gráfico 10, es el que presenta la mayor demanda de insumos importados entre los sectores que forman parte de la industria con tecnología diferenciada. Entre 2000 y 2014, su media de importación directa e indirecta fue de 0,30 dólares por dólar producido. Si bien su demanda directa e indirecta de insumos importados se redujo en forma acentuada en 2007, no se encontró una explicación para tal movimiento en la literatura. Se infiere que dicha reducción refleja un evento coyuntural, pues posteriormente los valores retomaron su tendencia ascendente. 


\section{Gráfico 10}

Brasil: valor de la demanda directa e indirecta de insumos importados de la industria con tecnología diferenciada por cada dólar producido por los sectores, 2000-2014

(En dólares)

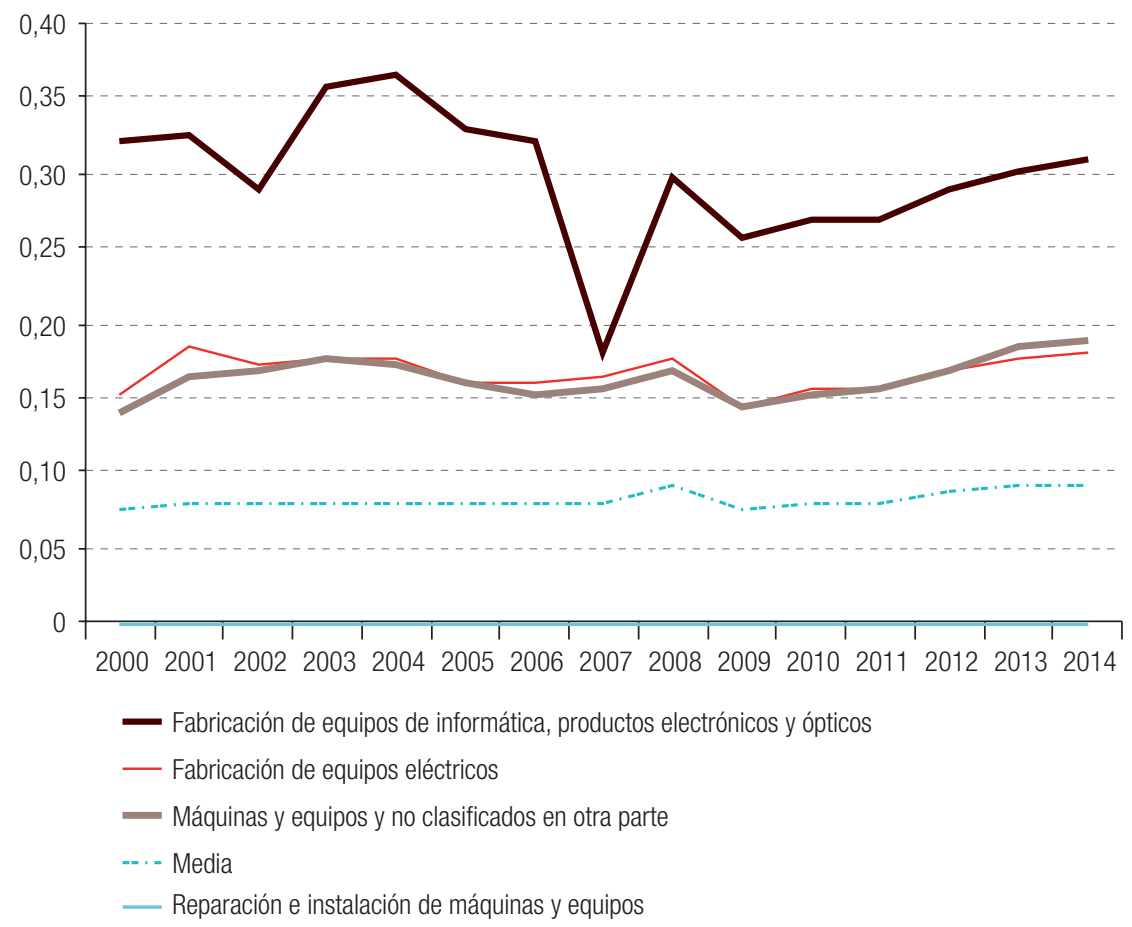

Fuente: Elaboración propia, sobre la base de información de la Base de Datos Mundial de Insumos-Productos (WIOD).

Cabe destacar que la principal dependencia externa del sector está ligada a la importación de insumos provenientes del propio sector de fabricación de equipos de informática, productos electrónicos y ópticos, que representa más de la mitad del valor de su requisito directo e indirecto de importación de bienes intermedios. No obstante, del gráfico 10 surge que, en el período examinado, el sector gradualmente sustituyó proveedores externos por internos. Esto resulta evidente al observar que, mientras la importación directa e indirecta de insumos importados llegaba a 0,36 dólares por dólar producido en 2003, ese valor disminuyó a 0,31 dólares en 2014. Lo mismo ocurre al analizar la dependencia de la economía con respecto a la importación de insumos de este sector, como se puede apreciar en el gráfico 11. 


\section{Gráfico 11}

Brasil: valor de la demanda directa e indirecta de insumos importados de la industria con tecnología diferenciada por cada dólar producido en la economía, 2000-2014

(En dólares)

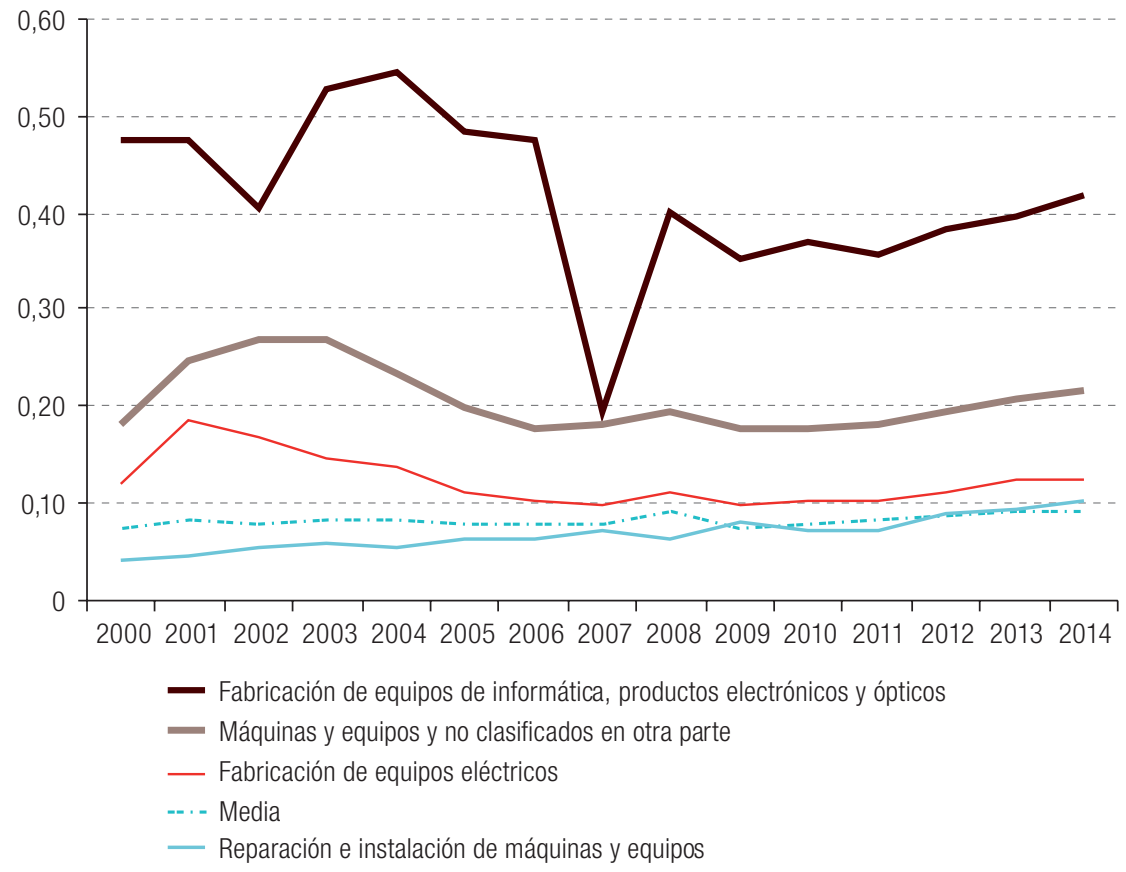

Fuente: Elaboración propia, sobre la base de información de la Base de Datos Mundial de Insumos-Productos (WIOD).

Al igual que los demás sectores de esta industria, el sector de equipos eléctricos se clasificó en general como tipo II. Esto significa que la producción del sector demanda insumos importados por encima de la media de la economía y que la economía en su conjunto depende de la importación de insumos provenientes de este sector para realizar sus actividades. La demanda media de insumos importados de este sector durante el período analizado fue de 0,17 dólares por dólar producido. Entre 2000 y 2014, la demanda de importación de insumos de este sector y del sector de máquinas y equipos se mantiene dentro de un determinado intervalo, como se puede observar en el gráfico10. Lo mismo ocurre al analizar la dependencia de la economía en relación con los insumos importados provenientes de este sector en el gráfico 11.

El sector de máquinas y equipos y no clasificados en otra parte se clasificó como de tipo II. En el período examinado, este sector importó una media de 0,16 dólares por cada dólar producido y más del 39\% de ese valor correspondía a la importación de máquinas y equipos, es decir, el sector demanda importación del propio sector. En forma análoga, la producción de la economía demanda insumos relacionados con este sector por encima de la media, como puede observarse en el gráfico 11, y el principal demandante es el propio sector de máquinas y equipos. Así, es posible afirmar que, al incrementarse la producción de este sector, en contrapartida se estimula la demanda de importación por encima de la media, aumentando la dependencia externa de la economía. Esta observación es válida para todos los sectores examinados en esta sección.

Por último, el sector de reparación e instalación de máquinas y equipos se clasificó como de tipo IV durante el período estudiado, es decir, un sector poco demandante y poco demandado. No obstante, en el gráfico 11 se observa que entre 2000 y 2014 la economía incrementó continuamente su dependencia de la importación de insumos relacionados con este sector para realizar sus actividades productivas, de manera que a partir de 2012 su clasificación pasó a ser de tipo I. 


\section{Panorama de la industria brasileña en relación con la dependencia de insumos importados}

Con el objetivo de sintetizar los resultados encontrados en esta investigación, en el cuadro 8 se presentan los 20 sectores industriales estudiados, enumerados de acuerdo con su clasificación según su demanda directa e indirecta de insumos importados.

Cuadro 8

Brasil: clasificación de los sectores industriales según su dependencia de insumos importados

\begin{tabular}{|c|c|c|}
\hline Clasificación & Demandantes & Poco demandantes \\
\hline \multirow{11}{*}{ Demandados } & Industria extractiva & \\
\hline & Coque y refinación de petróleo & \\
\hline & $\begin{array}{l}\text { Fabricación de productos metálicos } \\
\text { (excepto máquinas y equipos) }\end{array}$ & \\
\hline & Sustancias y productos químicos & \\
\hline & Caucho y productos plásticos & \\
\hline & Metales básicos & \\
\hline & Vehículos y afines & \\
\hline & Otros equipos de transporte & \\
\hline & Equipos de informática, productos electrónicos y ópticos & \\
\hline & Equipos eléctricos & \\
\hline & Máquinas y equipos y no clasificados en otra parte & \\
\hline \multirow{6}{*}{ Poco demandados } & Otros productos minerales no metálicos & Reparación e instalación de máquinas y equipos \\
\hline & Textil, prendas de vestir y productos de cuero & Madera, productos de madera y corcho, excepto muebles \\
\hline & Muebles y afines & \\
\hline & Papel y productos de papel & \\
\hline & $\begin{array}{l}\text { Impresión y reproducción de medios } \\
\text { Productos alimenticios, bebidas y tabaco }\end{array}$ & \\
\hline & Farmacéutico y productos farmacéuticos & \\
\hline
\end{tabular}

Fuente: Elaboración propia.

En el cuadro 8 se observa que la mayor parte de los sectores industriales brasileños se clasifican como demandantes y demandados, es decir, sectores cuya producción demanda directa e indirectamente insumos importados por encima de la media de la economía. Por lo tanto, es importante notar que, al estimular la producción industrial, en contrapartida se estimulan directa e indirectamente las importaciones. De la misma forma, cuando la producción de la economía se incrementa, se estimulan las importaciones provenientes de los sectores listados en el primer cuadrante del cuadro 8 por encima de la media de la economía. Esto refleja el alto grado de dependencia del sector externo de la estructura productiva industrial.

En contraposición, la economía presenta bajos niveles de dependencia con respecto a la importación de insumos provenientes de la industria alimentaria. Sato (1997) sostiene que, después del Plan Real (que se tradujo en un aumento real en los ingresos de los trabajadores), el sector de alimentos presentó ganancias significativas y que el período también se caracterizó por fusiones y adquisiciones que llevaron a la expansión del sector. Gouveia (2006) señala la importancia de la industria alimentaria para la economía del país, dado que emplea a cerca de 1 millón de trabajadores, 
fue responsable del 15\% de la facturación del sector industrial en 2006 y tiene gran relevancia en la generación de saldos comerciales positivos. Así, se puede afirmar que los efectos indirectos intersectoriales generados por estos sectores son en gran medida apropiados por el sector interno.

Como motivo de preocupación cabe señalar que muchos de los sectores industriales más dinámicos y de mayor capacitación tecnológica - pertenecientes a las industrias diferenciadas e intensivas en escala, así como al sector de refinación de petróleo- presentan altos niveles de dependencia externa (están en la primera parte del cuadro 8). En consecuencia, parte del dinamismo generado por estos sectores deja de ser apropiado por la economía nacional, no solo debido a sus altos requisitos directos e indirectos de importación de insumos, sino también en virtud de que los demás sectores de la economía dependen de la importación de insumos provenientes de estas industrias para incrementar su producción.

\section{Consideraciones finales}

La industria constituye un sector de primordial importancia para el desempeño económico de un país, dada su capacidad de producir efectos indirectos intersectoriales en materia de empleo, ingresos y tecnología. No obstante, en las últimas décadas se ha evidenciado en el Brasil un proceso por el cual la industria aumenta gradualmente su dependencia del sector externo, en la medida en que incorpora un gran número de insumos importados en su producción. Esto debilita los eslabones industriales preexistentes y dificulta la formación de otros nuevos, limitando su capacidad de encadenamiento y profundizando la dependencia externa del país.

El objetivo del presente estudio ha sido analizar la dependencia sectorial de insumos importados de la industria brasileña entre 2000 y 2014. Los resultados permitieron identificar las actividades cuya dependencia del resto del mundo es relevante en términos de demanda de importación, es decir, que dependen del exterior para incrementar su nivel de producción, así como conocer los sectores del exterior de los cuales la economía tiene mayor dependencia, es decir, los más presentes en el flujo de importaciones cuando crece la producción interna.

Se constató que, en general, los sectores industriales brasileños dependen de la importación de bienes intermedios para ampliar su nivel de producción. Es interesante señalar que, como se pudo observar en los análisis gráficos, la dependencia externa de la industria brasileña se intensificó en las dos últimas décadas, debido a los efectos de la apertura económica realizada conjuntamente con una política de apreciación cambiaria. Esto se tradujo en un mayor incentivo a la sustitución de proveedores nacionales por extranjeros, debido a la incapacidad de la industria nacional para competir con el contenido importado. El cambio y la intensiva reducción de las barreras arancelarias y no arancelarias facilitaron el acceso a las mercaderías extranjeras, que al representar menores costos para las empresas nacionales terminaron por permear el tejido industrial de forma continua, como se pudo apreciar en el análisis de los resultados. El proceso de sustitución de proveedores internos por externos no se invirtió en la década de 2000 sino que, por el contrario, se mantuvo, posiblemente debido a la reestructuración productiva de la década anterior y a la continuidad de la política de apreciación cambiaria.

De este modo, se puede afirmar que una parte importante de los efectos indirectos generados por la producción industrial brasileña es apropiada por el sector externo, en la medida en que parte de las lagunas de la matriz industrial se colma mediante bienes intermedios importados. Asimismo, se destaca que los principales sectores demandantes de insumos importados son aquellos en cuya producción se incorpora mayor contenido tecnológico, como las industrias diferenciadas, intensivas en escala y el sector de refinación de petróleo. 
No obstante, cabe subrayar las limitaciones del método aquí utilizado, que pueden verificarse en el trabajo de Schuschny (2005, pág. 26) y se relacionan con la propia construcción de la matriz de insumo-producto, que agrega un número considerable de productos en sectores admitiendo el presupuesto de la sustituibilidad perfecta entre los factores de producción. Además, al asumir la construcción de coeficientes técnicos fijos se eliminan las posibilidades de que los sectores obtengan ganancias de (des)economías de escala. Por último, las carencias de las matrices se colman mediante valores monetarios y, de ese modo, se supone la perfecta homogeneidad en el sistema de precios entre los sectores, un hecho que no se verifica en la práctica.

\section{Bibliografía}

Aurea, A. P. y A. C. F. Galvão (1998), "Importação de tecnologia, acesso às inovações e desenvolvimento regional: o quadro recente no Brasil", Texto para Discussão, № 616, Brasilia, Instituto de Investigación Económica Aplicada (IPEA).

Bonelli, R. y R. Fonseca (1998), "Ganhos de produtividade e de eficiência: novos resultados para a economia brasileira", Pesquisa e Planejamento Econômico, vol. 28, Río de Janeiro, Instituto de Investigación Económica Aplicada (IPEA).

Brógio, A. (2002), "O comércio intrafirma na indústria farmacêutica brasileira", Pensamento \& Realidade, vol. 11, São Paulo.

Canchumani, R. M. L. (2009), "A produção de fármacos e medicamentos no Brasil e na Índia: uma análise comparativa (1995-2001)" [en línea] http://bibliofarma.com/download/13087/.

Cardoso, E. (2001), "A crise monetária no Brasil: migrando da âncora cambial para o regime flexível", Revista de Economia Política, vol. 21, № 3, São Paulo, Centro de Economía Política.

Carvalho, P. G. y C. A. Feijó (2000), "Produtividade industrial no Brasil: o debate recente", Indicadores Econômicos FEE, vol. 28, № 3.

Chenery, H. B., S. Robinson y M. Syrquin (1986), Industrialization and Growth: A Comparative Study, Washington, D.C., Banco Mundial.

Coutinho, L. (1997), "A especialização regressiva: um balanço do desempenho industrial pós-estabilização", Brasil: desafios de um país em transformação, J. P. R. Velloso (org.), Río de Janeiro, José Olympio.

Feijó, C. A., P. G. Carvalho y J. S. G. Almeida (2005), "Ocorreu uma desindustrialização no Brasil?", Instituto de Estudios para el Desarrollo Industrial (IEDI) [en línea] https://iedi.org.br/admin_ori/pdf/20051129_ desindustrializacao.pdf.

Fonseca, R. (2010), "Valorização cambial no Brasil e as armas para defender a indústria na guerra cambial", Revista Brasileira de Comércio Exterior, № 105, Río de Janeiro, Fundación Centro de Estudios de Comercio Exterior (FUNCEX).

Fonseca, R., M. C. Carvalho Jr. y H. Pourchet (1998), "A orientação externa da indústria de transformação brasileira após a liberalização comercial”, Texto para Discussão, № 135, Río de Janeiro, Fundación Centro de Estudios de Comercio Exterior (FUNCEX).

Furtado, C. (1964), Desarrollo y subdesarrollo, Buenos Aires, Editorial Universitaria.

Gereffi, G., J. Humphrey y T. Sturgeon (2005), "The governance of global value chains", Review of International Political Economy, vol. 12, № 1, Abingdon, Taylor \& Francis.

Gorini, A. P. F. y S. H. Siqueira (1997), "Complexo têxtil brasileiro" [en línea] https://www.bndes.gov.br/ SiteBNDES/export/sites/default/bndes_pt/Galerias/Arquivos/conhecimento/bnset/bsesptex.pdf.

Gouveia, F. (2006), "Indústria de alimentos: no caminho da inovação e de novos produtos", Inovação Uniemp, vol. 2, N 5, Campinas, Instituto Uniemp.

Guilhoto, J. J. M. (2004), "Análise de insumo e produto: teoria e fundamentos", São Paulo, Universidad de São Paulo.

Hirschman, A. O. (1961), La estrategia del desarrollo económico, Ciudad de México, Fondo de Cultura Económica.

Ishikawa, J. (1992), "Trade patterns and gains from trade with an intermediate good produced under increasing returns to scale", Journal of International Economics, vol. 32, № 1, Amsterdam, Elsevier.

Kaldor, N. (1957), "A model of economic growth", The Economic Journal, vol. 67, № 268, Wiley. 
Kon, A. y D. C. Coan (2009), "Transformações da indústria têxtil brasileira: a transição para a modernização", Revista de Economia Mackenzie, vol. 3, № 3.

Lastres, H. M. M. y J. E. Cassiolato (2000), "Sistemas de inovação: políticas e perspectivas", Parceiras Estratégicas, vol. 5, № 8.

Levy, P. M. y M. I. F. Serra (2002), "Coeficientes de importação e exportação na indústria", Boletim de Conjuntura, № 58, Río de Janeiro, Instituto de Investigación Económica Aplicada (IPEA).

Magacho, G. R. (2013), "Incorporating import coefficients into a structural decomposition analysis: an empirical investigation on Brazilian growth sources" [en línea] https://www3.eco.unicamp.br/neit/images/ Downloads/seminarioagosto13.pdf.

(2010), "Desarticulação das cadeias produtivas no Brasil: impacto sobre a geração de emprego e a renda (1995-2008)", Boletim NEIT, № 15, Campinas, Instituto de Economía, Universidad Estadual de Campinas.

Maia, K. (2001), "Progresso tecnológico, qualificação da mão-de-obra e desemprego", tesis, Brasilia, Departamento de Economía, Universidad de Brasilia.

Marconi, N. y F. C. Barbi (2010), "Taxa de câmbio e composição setorial da produção: sintomas de desindustrialização da economia brasileira", Texto para Discussão, № 255, São Paulo, Escuela de Economía de São Paulo de la Fundación Getulio Vargas.

Marconi, N. y M. Rocha (2012), "Taxa de câmbio, comércio exterior e desindustrialização precoce - o caso brasileiro", Economia e Sociedade, vol. 21, número especial, Campinas, Universidad Estadual de Campinas.

Miller, R. E. y P. D. Blair (2009), Input-Output Analysis: Foundations and Extensions, Nueva York, Cambridge University Press.

Montebello, A. E. S. y C. J. C. Bacha (2011), "O setor de celulose e papel na economia brasileira", O Papel, vol. 72, № 4, São Paulo.

Morceiro, P. (2012), "Desindustrialização na economia brasileira no período 2000-2011: abordagens e indicadores", São Paulo, Cultura Acadêmica.

Morceiro, P., R. Gomes y G. R. Magacho (2014), "Conteúdo importado na produção industrial e na demanda final do Brasil recente: uma proposta de indicadores de importação e de conteúdo nacional/ estrangeiro", Anais do XL Encontro Nacional de Economia, Asociación Nacional de Centros de Posgrado en Economía (ANPEC).

Moreira, M. (1999), "A indústria brasileira nos anos 90: o que já se pode dizer", A economia brasileira nos anos 90, F. Giambiagi y M. M. Moreira (orgs.), Río de Janeiro, Banco Nacional de Desarrollo Económico y Social (BNDES).

Moreira, M. y S. Najberg (1998), “Abertura comercial: criando ou exportando empregos?”, Pesquisa e Planejamento Econômico, vol. 28, № 2, Río de Janeiro, Instituto de Investigación Económica Aplicada (IPEA).

Nakabashi, L., F. D. Scatolin y M. J. V. da Cruz (2010), "Impactos da mudança estrutural da economia brasileira sobre o seu crescimento", Revista de Economia Contemporânea, vol. 14, № 2, Río de Janeiro, Instituto de Economía, Universidad Federal de Río de Janeiro (UFRJ).

Nassif, A. (2008), "Há evidências de desindustrialização no Brasil?", Revista de Economia Política, vol. 28, № 1, São Paulo, Centro de Economía Política.

OCDE (Organización de Cooperación y Desarrollo Económicos) (2005), Science, Technology and Industry Scoreboard 2005, París.

Oreiro, J. L. y C. A. Feijó (2010), "Desindustrialização: conceituação, causas, efeitos e o caso brasileiro", Revista de Economia Política, vol. 30, № 2, São Paulo, Centro de Economía Política.

Pavitt, K. (1984), "Sectoral patterns of technical change: towards a taxonomy and a theory", Research Policy, vol. 13, № 6, Amsterdam, Elsevier.

Prebisch, R. (1949), "El desarrollo económico de América Latina y algunos de sus principales problemas" (E/CN.12/89), Santiago, Naciones Unidas.

Rangel, A. S., M. M. Silva y B. K. Costa (2010), "Competitividade da indústria têxtil brasileira", Revista de Administração e Inovação, vol. 7, № 1, São Paulo, Universidad de São Paulo.

Rossi Júnior, J. L. y P. C. Ferreira (1999), "Evolução da produtividade industrial brasileira e abertura comercial”, Texto para Discussão, № 651, Río de Janeiro, Instituto de Política Económica Aplicada (IPEA).

Sá Porto, P. C., O. Canuto y A. A. L. Mota (2017), "As possibilidades de inserção do Brasil nas cadeias globais de valor", Informe GEPEC, vol. 21, № 1, Toledo, Paraná, Universidad Estadual del Oeste de Paraná.

Sato, G. S. (1997), "Perfil da indústria de alimentos no Brasil: 1990-97", Revista de Administração de Empresas, vol. 37, № 3, São Paulo. 
Schuschny, A. R (2005), "Tópicos sobre el modelo de insumo-producto: teoría y aplicaciones", serie Estudios Estadísticos y Prospectivos, № 37 (LC/L.2444-P), Santiago, Comisión Económica para América Latina y el Caribe (CEPAL).

Soares, S., L. M. S. Servo y J. S. Arbache (2001), "O que (não) sabemos sobre a relação entre abertura comercial e mercado de trabalho no Brasil”, Texto para Discussão, № 843, Río de Janeiro, Instituto de Investigación Económica Aplicada (IPEA).

Thorstensen, V., L. Ferraz y L. Gutierre (2014), "O Brasil nas cadeias globais de valor", Dossiê, edición especial, vol. 2, año 13, Centro Brasileño de Relaciones Internacionales (CEBRI).

UNCTAD (Conferencia de las Naciones Unidas sobre Comercio y Desarrollo) (2013), World Investment Report. Global Value Chains: Investment and Trade for Development (UNCTAD/WIR/2013), Nueva York, Naciones Unidas.

Veeramani, C. (2009), "Impact of imported intermediate and capital goods on economic growth: a cross country analysis" [en línea] https://papers.ssrn.com/sol3/Delivery.cfm/SSRN_ID1325181_code729291. pdf?abstractid=1325181\&mirid $=1$. 